\title{
A Case Series of Intraneural Ganglion Cyst Involving the Common Peroneal Nerve: Potential Cause for Foot Drop
}

Naved Ahmad ${ }^{1}$, Huma Raiyan Khan ${ }^{2}$, Khizer Hussain Afroze M *3, Saifer Khan ${ }^{4}$, Nisar Ansari ${ }^{5}$, Karan Bedmudha ${ }^{6}$.

${ }^{1}$ Assistant Professor, Department of Orthopedics, Hind Institute of Medical Sciences, Lucknow, Uttar Pradesh, India

${ }^{2}$ Junior Resident, Department of Obstetrics and Gynaecology, RMLIMS, Lucknow, Uttar Pradesh, India.

${ }^{* 3}$ Assistant Professor, Department of Anatomy, MVJ Medical College \& Research Hospital, Hoskote, Bangalore, Karnataka. India.

${ }^{4}$ Assistant professor, Department of Orthopedics, Hind Institute of Medical Sciences, Lucknow, Uttar Pradesh, India

${ }^{5}$ Assistant professor, Department of Orthopedics, Hind Institute of Medical Sciences, Lucknow, Uttar Pradesh, India

${ }^{6}$ Junior Resident, Department of Orthopedics, Hind Institute of Medical Sciences, Lucknow, Uttar Pradesh, India.

\section{ABSTRACT}

Background: Intraneural ganglion cysts (IGC) are non-neoplastic mucinous cysts that form when thick mucinous fluid accumulates in the epineurium of peripheral nerves, with the majority of cases occurring in the para-articular or articular areas.

Case Presentation: The two cases of a 69-year-old man and a 59-year-old man who acquired peroneal nerve neuropathy as a result of an intraneural ganglion cyst are presented here. The L.L.R.M. Medical College Department of Orthopedics provided care for them. There was complete nerve recovery in all patients after substantial cyst wall dissection and secretion removal.

Conclusion: An intraneural ganglion cyst and trauma may exacerbate nerve damage, despite the fact that it is difficult to detect the cyst before surgery. An early diagnosis and prophylactic actions are typically associated with better outcomes.

KEY WORDS: Intraneural ganglion, Common peroneal nerve, Foot drop.

Corresponding Author: Dr. Khizer Hussain Afroze M, Assistant Professor, Department of Anatomy, MVJ Medical College \& Research Hospital, Hoskote, Bangalore, Karnataka. India. 572114 E-Mail: drafroze.homoeo@gmail.com

Access this Article online

Quick Response code

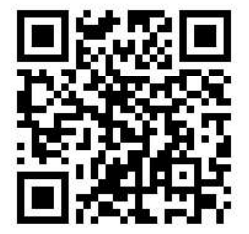

DOI: 10.16965/ijar.2021.184

\begin{tabular}{|c|c|c|}
\hline \multicolumn{3}{|c|}{ Journal Information } \\
\hline \multicolumn{3}{|c|}{$\begin{array}{l}\text { International Journal of Anatomy and Research } \\
\text { ISSN (E) 2321-4287 | ISSN (P) 2321-8967 } \\
\text { https://www.ijmhr.org/ijar.htm } \\
\text { DOI-Prefix: https://dx.doi.org/10.16965/ijar } \quad \text { (cc) EY-W0-si }\end{array}$} \\
\hline \multicolumn{3}{|c|}{ Article Information } \\
\hline $\begin{array}{l}\text { Received: } 19 \text { Oct } 2021 \\
\text { Peer Review: } 20 \text { Oct } 2021 \\
\text { Revised: None }\end{array}$ & $\begin{array}{l}\text { Accepted: } 23 \text { Nov } \\
\text { Published (O): } 05 \\
\text { Published (P): } 05\end{array}$ & $\begin{array}{l}21 \\
\text { c } 2021 \\
2021\end{array}$ \\
\hline
\end{tabular}

of peripheral nerves, with the majority of cases occurring in the para-articular or articular areas [1-3]. The common peroneal nerve (CPN) is the most usually impacted nerve in the body,

\section{INTRODUCTION}

Intraneural ganglion cysts (IGC) are non-neoplastic mucinous cysts that form when thick mucinous fluid accumulates in the epineurium 
while the ulnar and radial nerves are the most typically affected nerves in the upper extremities [1-6].

Because of the displacement and compression of the nerve fascicles, intraneural ganglion cysts often induce signs and symptoms of peripheral neuropathy. It's important to differentiate this condition from other kinds of peripheral nerve compression since early discovery and diagnosis leads to better surgical results [7]. Local or radiating pain, paresthesia's, weakness, and muscular atrophy are symptoms that result from mechanical compression of neighboring nerve fascicles caused by the IGC [2]. Magnetic resonance imaging (MRI) is the study of choice for diagnosis of an IGC [5].

The pathophysiology of this ailment is debatable, and it was never fully elucidated in the past. Distinct ideas have led to the development of multiple therapeutic techniques based on different pathogenesis of cyst formation. ${ }^{1}$ We present the cases ofmen with 69 \& 59 -year-old who developed peroneal nerve neuropathy as a result of an intraneural ganglion cyst.

\section{CASE PRESENTATION}

This study was conducted in accordance with the ethical standards of the Institutional Review Board of our institution, L.L.R.M. Medical College, Meerut of Department of orthopedic
CASE 1: A 69-year-old man presented to our OPD with left leg pain and foot drop that had been plaguing him for more than a year. The pain was accompanied by atypical, slowly progressive, localized soft swelling over lateral aspect of left knee with tingling sensation, heaviness and motor weakness over the left ankle and foot with left lower limb power grading of L2- 5/5, L3-5/5, L4-0/5, L5-0/5, S1-0/5. The swelling was approximately of the size $5 \mathrm{~cm}$ $X 3 \mathrm{~cm}$. (Figure $1 \& 2$ ).

The patient could not execute dorsiflexion and eversion throughout the assessment. There was no sensory loss over the left foot. On palpation, the swelling was soft, sensitive, and had a regular border, and it was located immediately below the head of the fibula. A non-contrast MRI of the left knee revealed a thin-walled, multi-loculated cystic lesion measuring $4 \mathrm{~cm} \times 1.7 \mathrm{~cm} \times 6 \mathrm{~cm}$ along the lateral and posterior aspects of the left tibio-fibular joint proximally with mild degeneration of joint. The lesion is considered to have a large impact on CPN.

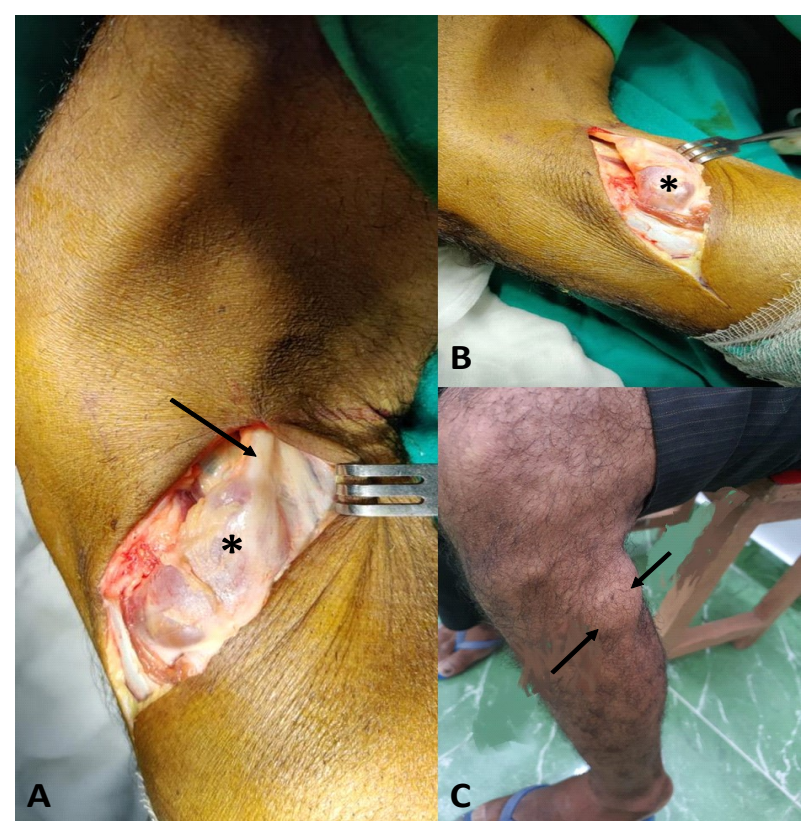

Fig. 1: Pre-operative and intraoperative photographs showing an oedematous common peroneal nerve with intraneural ganglion cyst (Black Asterisk). Common Peroneal nerve (Black arrow). 


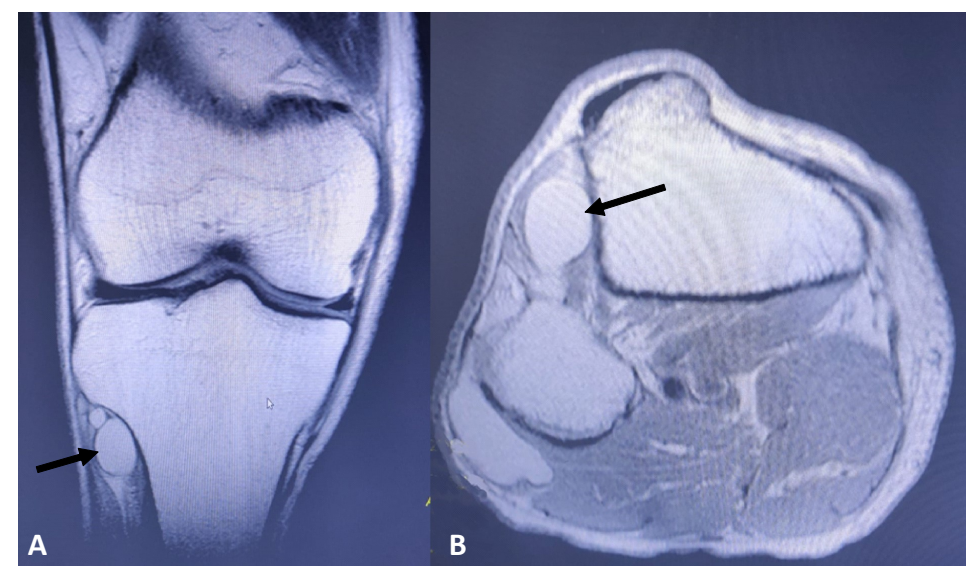

Fig. 1a: MRI images of the knee at the level of the tibiofibular joint showing intraneural ganglion cyst. A) Coronal section B) Axial.

CASE 2: A 59-year-old male patient presented at our hospital with complaints of pain in his right lateral knee and an acute foot drop. A physical examination revealed that the right ankle had complete foot dorsiflexion. Dorsiflexion of the ankle and significant great toe extension were considerably hampered.
There was no evidence of disc herniation, spinal stenosis, or foraminal stenosis on magnetic resonance imaging (MRI) of the lumbar spine. A subsequent MRI of the right knee revealed intraneural ganglion cysts common peroneal nerve which extend up to the level of its bifurcation measuring about $3.7 \mathrm{~cm} \times 1.8 \mathrm{~cm} \times 5.4 \mathrm{~cm}$. (Figure $3 \& 4$ )
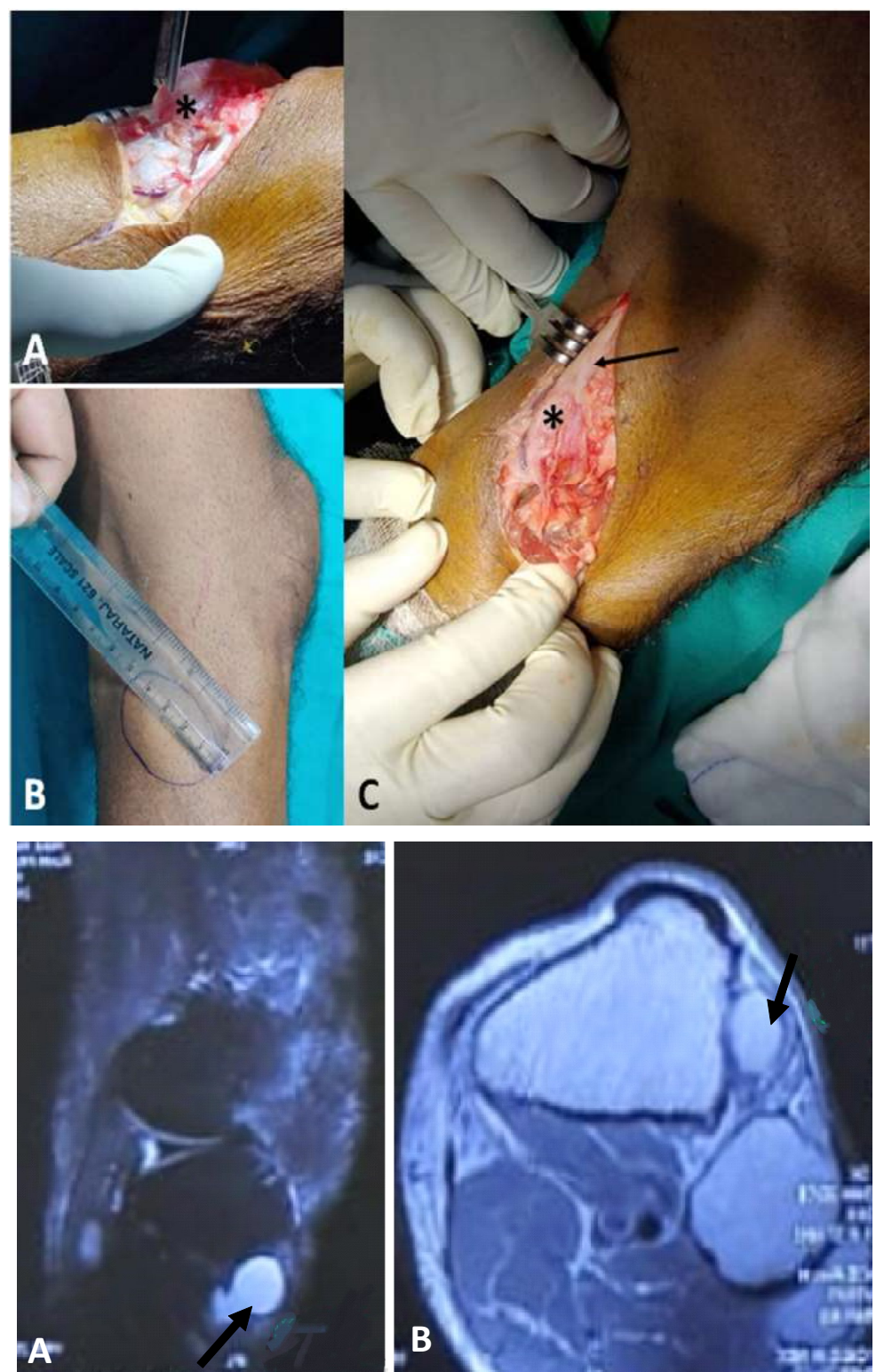

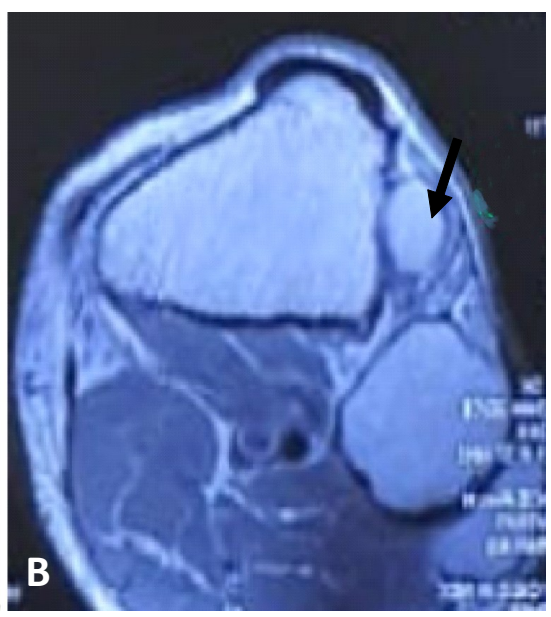

Fig. 2: Pre-operative and intraoperative photographs showing an oedematous common peroneal nerve with intraneural ganglion cyst (Black Asterisk). Common Peroneal nerve (Black arrow)

Fig. 2a: MRI images of the knee at the level of the tibiofibular joint showing intraneural ganglion cyst. A) Coronal section B) Axial 
Naved Ahmad et al., A Case Series of Intraneural Ganglion Cyst Involving the Common Peroneal Nerve: Potential Cause for Foot Drop.

Table 1: Characteristics of cases with intraneural ganglion cyst.

\begin{tabular}{|c|c|c|}
\hline Characteristics & Case1 & Case 2 \\
\hline Age & 69 years & 59 years \\
\hline Gender & Male & Male \\
\hline Clinical Manifestation & $\begin{array}{l}\text { localised swelling over the lateral aspect of left } \\
\text { Knee, Lost of dorsiflexion and eversion }\end{array}$ & $\begin{array}{l}\text { swelling over posterolateral aspect of Right knee } \\
\text { upto the level of bifurcation of CPN, weakness in } \\
\text { ankle and toe dorsiflexion ( power grade-IV), No } \\
\text { sensory deficit }\end{array}$ \\
\hline Duration & More than a year & 3 months \\
\hline Extent & Upto the head of fibula & $\begin{array}{l}\text { Up to the level of bifurcation of common peroneal } \\
\text { nerve }\end{array}$ \\
\hline Size (MRI) & $4 \mathrm{~cm} \times 1.7 \mathrm{~cm} \times 6 \mathrm{~cm}$ & $3.7 \mathrm{~cm} \times 1.8 \mathrm{~cm} \times 5.4 \mathrm{~cm}$ \\
\hline
\end{tabular}

In both the cases, the tibial head of peroneal longus was reflected after incising skin and superficial fascia under aseptic precautions and spinal anaesthesia, a 7-cm lazy S-shaped incision was made just proximal and posterior to the head of the fibula, traversing towards the shaft of the tibia distally. The anterior and posterior crural intermuscular septum was resected and the septum between extensor hallucis longus and tibialis anterior was also resected to mobilize the nerve. A $4 \mathrm{X}$ $1.7 \times 6 \mathrm{cms}$, and $3.7 \mathrm{~cm} \times 1.8 \mathrm{~cm} \times 5.4 \mathrm{~cm}$ intraneural swelling was visualized in case 1 \& case 2 respectively. A small nick incision along the course of nerve was given to decompress the cyst. A gelatinous fluid approximately $5 \mathrm{ml}$ in case 1 and $4 \mathrm{ml}$ in case 2 came out from the cyst. The gelatinous material obtained was sent for HPE to verify diagnosis. It was suggestive of a ganglion cyst.

\section{DISCUSSION}

Ganglionic cysts, which are uncommon, are the source of peripheral nerve lesions [8]. The surgical literature has recorded the few incidences of lower extremities compression following Sultan's first description of peroneal nerve neuropathy in $1921 .{ }^{\circ} \mathrm{CPN}$ has the root values $L 4, L 5, S 1$, and $S 2$ and is one of the primary and terminal branches of the sciatic nerve. The CPN begins near the superior angle of the popliteal fossa and is most likely to get injured at the fibular tunnel's entrance, where it passes superficially to the lateral side of the fibula, considerably distal to the fibular head, with little soft tissue protection [8].

Many theories have been proposed. Spinner et al. presented the unified articular hypothesis, which emphasises the relevance of the articular branch in the pathophysiology of an endoneural ganglion cyst. According to their hypothesis, the cyst formed in an adjacent joint. Through a one-way valve mechanism, synovial fluid enters the articular branch through a capsular defect (traumatic or degenerative) and proceeds proximally, dissecting the epineurium, until it reaches the nerve's main trunk [13]. Primary ascent, sciatic nerve cross-over, and terminal branch descent were recognized as three distinct stages of peroneal intraneural ganglia cyst development by Spinner et al [13].

Rawal et al. proposed a very identical explanation, claiming that the peroneal nerve ganglia originate from the proximal tibiofibular joint through the articular branch [11].

Ganglia are mucin- or fluid-filled cystic formations bordered by flat spindle-shaped cells. Joint capsules, ligaments, tendon sheaths, bursae, and subchondral bone can all produce ganglia.

Nerve irritation symptoms such as numbness, tingling, and pain in the afflicted nerve's distribution are frequent with ganglion cysts. Patients with peroneal nerve palsies frequently complain of difficulty walking due to paretic or paralysed ankle dorsiflexors. The anterior and lateral compartments of the leg muscles are both weak, resulting in a steppage gait pattern. To clear the afflicted foot during the swing phase of ambulation, it requires an additional lift from the ground $[1,2]$.

While pain is not universal, when it happens, it is usually connected to the specific area of CPN compression or its branches (superficial or deep). Sensory testing usually indicates a problem with the superficial and deep peroneal nerves' cutaneous distribution. Tinel's sign is usually positive in the peroneal nerve's 
sensory distribution [1].

For the diagnosis of intraneural ganglion cysts, an $\mathrm{MRI}$ is recommended since it allows for thorough characterisation of the related anatomy. The whole area of the lesion may be identified with precision, and the nerve fascicles can be viewed in greater detail. Furthermore, the effects of muscular denervation may be clearly seen [5].

Surgical treatment is undoubtedly the first-choice treatment for a peroneal intraneural ganglion. No authors has advocated for conservative treatment because surgical treatment is usually successful when started early [14]. Ultrasound-guided aspirations, cyst resection, neurolysis, and articular branch disconnection are among the surgical options that have been documented. The most usual technique is surgery exploration and decompression of the peroneal nerve. The most usual technique is surgery exploration and decompression of the peroneal nerve [15].

Surgical treatment has historically resulted in poor results and high rates of recurrence, which have been reported to be as high as $11 \%[8]$.

After unilateral cyst treatment i.e decompression without articular branch disconnection, Desy et al. observed a 13 percent recurring rate. Recurrence was decreased by $6 \%$ with articular branch ligation or disconnection, and there was no intraneural recurrence after surgical procedures to repair the adjacent joint [8,13].

According to Fabre et al. [16], surgical decompression was used to treat 60 patients with peroneal nerve palsies, many of which were idiopathic. In 87 percent of those who had both sensory and motor involvement before to surgery, postoperative motor function was good to excellent. If the complaints have been confirmed by electrophysiological testing, decompression is indicated even for patients who just experience sensory difficulties. Traction injuries and perineural fibrosis with incomplete function recovery are other concerns. Nerve transection is a less common complication that results in irreversible disability [9].
Muramatsu et al. offered five essential factors for successful treatment of peroneal intraneural ganglion: early MRI identification, surgery within four months of onset of foot drop, simple exoneural dissection, microsurgical epineurotomy and cyst draining, and disconnection of the articular branch [14].

\section{CONCLUSION}

We recognize and acknowledge the articular (synovial) theory, which hypothesizes that the genesis of these pathologies is explained by it. Surgical treatment should focus on either the joint or the joint connection (articular branch). By adhering to these guidelines, the risk of iatrogenic nerve injury and cyst recurrence can be reduced, and patient outcomes can be improved. Although the cyst is difficult to diagnose before an operation, the combination of an intraneural ganglion cyst and trauma may aggravate nerve injury. Early diagnosis and preemptive measures are frequently linked to positive outcomes.

\section{Conflicts of Interests: None}

\section{REFERENCES}

[1]. Desy NM, Wang H, Elshiekh MA, et al. Intraneural ganglion cysts: A systematic review and reinterpretation of the world's literature. J Neurosurg. 2016;125:615-630.

[2]. Buckley CE, Tong E, Spence LD, et al. Intraneural ganglion cyst involving the tibial nerve-a case report. BJR Case Rep. 2017;3:20160116.

[3]. Fricke T, Schmitt AD, Jansen O. Intraneural ganglion cysts of the lower limb. Rofo. 2019;191:732-738.

[4]. Wilson TJ, Hebert-Blouin MN, Murthy NS, et al. The nearly invisible intraneural cyst: A new and emerging part of the spectrum. Neurosurg Focus 2017;42:E10.

[5]. Silveira CRS, Vieira CGM, Pereira BM, et al. Cystic degeneration of the tibial nerve: Magnetic resonance neurography and sonography appearances of an intraneural ganglion cyst. Skeletal Radiol. 2017;46:1763-1767.

[6]. Spinner RJ, Mikami Y, Desy NM, et al. Superficial radial intraneural ganglion cysts at the wrist. Acta Neurochir (Wien). 2020;160;2479-2484.

[7]. Lang CJ, Neubauer U, Qaiyumi S, Fahlbusch R. Intraneural ganglion of the sciatic nerve: detection by ultrasound. J Neurol Neurosurg Psychiatry. 1994. July; 57(7): 870-1

[8]. Desy NM, Lipinski LJ, Tanaka S, et al. Recurrent intraneural ganglion cysts: Pathoanatomic patterns and treatment implications. Clin Anat. 2015;28:1058-1069. 
[9]. R. J. Greer-Bayramoglu, A. S. Nimigan Bsc, and B. S. Gan.mCompression neuropathy of the peroneal nerve secondary to a ganglion cyst. Canadian Journal of Plastic Surgery 2008;16(3):181-183.

[10]. F. de Schrijver, J. P. Simon, L. de Smet, and G. Fabry. Ganglia of the superior tibiofibular joint: report of three cases and review of the literature. Acta Orthopaedica Belgica 1998;64(2):233-241.

[11]. A. Rawal, K. R. Ratnam, Q. Yin, C. Sinopidis, and S. P. Frostick. Compression neuropathy of common peroneal nerve caused by an extraneural ganglion: a report of two cases," Microsurgery, vol. 24, no. 1, pp. 63-66, 2004.

[12]. Spinner RJ, Amrami KK, Wang $\mathrm{H}$, et al. Cross-over: A generalizable phenomenon necessary for secondary intraneural ganglion cyst formation. Clin Anat. 2008;21:111-118.
[13]. Spinner RJ Atkinson JLD Scheithauer BW Rock MG Birch R Kim TA et al. Peroneal intraneural ganglia: the importance of the articular branch. Clinical series. J Neurosurg. 2003. August; 99(2): 319-29.

[14].Spinner RJ, Scheithauer BW, Amrami KK. The unifying articular (synovial) origin of intraneural ganglia: evolution-revelation-revolution. Neurosurgery. 2009. October; 65(4 Suppl): A115-124.

[15]. Keser N, Akpinar P, Is M, Aktas I. Irreversible footdrop as a consequence of neglected knee pain in an adolescent with a peroneal intraneural ganglion cyst. World Neurosurg. 2018. March; 111: 307-10.

[16]. T. Fabre, C. Piton, D. Andre, E. Lasseur, and A. Durandeau. Peroneal nerve entrapment. Journal of Bone and Joint Surgery-Series A, 1998;80(1):4753.

\section{How to cite this article:}

Naved Ahmad, Huma Raiyan Khan, Khizer Hussain Afroze M, Saifer Khan, Nisar Ansari, Karan Bedmudha. A Case Series of Intraneural Ganglion Cyst Involving the Common Peroneal Nerve: Potential Cause for Foot Drop. Int J Anat Res 2021;9(4):8189-8194. DOI: 10.16965/ijar.2021.184 